\title{
Darwin and Moral Realism: Survival of the Iffiest
}

\author{
Knut Olav Skarsaune
}

Penultimate draft; please cite official version at Springer / Philosophical Studies: http:/ /link.springer.com/article/10.1007\%2Fs1 1098-009-9473-8

It takes steady epistemic nerves to be a moral realist. Not only do we tend to struggle with our positive accounts of how moral knowledge is possible; we must also face a recent, powerful argument which is intended to show that we needn't even bother trying: it is clear beforehand that we are bound to fail. From the premise that evolutionary pressures have had a tremendous (though indirect) impact on the content of our evaluative beliefs, Street (2006) argues that realists are faced with a Darwinian dilemma: they must either assert or deny that there is a relation between evolutionary pressures and the evaluative facts. If realists assert a relation, they are forced to advance a "tracking account," according to which evolution has bestowed upon us an ability to "track," or grasp, the evaluative facts, because this ability is reproductively advantageous. Street objects that there is no reproductive pay-off in grasping evaluative facts, as realists conceive of them. On the other hand, if realists deny that there is such a relation, then they are forced to the unacceptably sceptical conclusion that many or most of our evaluative beliefs are probably false (I'll present the argument more fully below).

In this paper, I offer a realist response to Street's challenge. I do not take a stand on whether there is a relation between evolutionary pressures and the evaluative facts. Instead, I argue by separation of cases: I argue, on the one hand, 
that if pleasure is usually good and pain usually bad, then the required relation between evolutionary pressures and the evaluative facts (realistically understood) exists. On the other hand, I argue that it is philosophically harmless for realists to be committed to the proposition that, if it is not the case that pleasure is usually good and pain usually bad, then many or most of our evaluative beliefs are probably false. Harmless, first, because this proposition is true, and second, because realists would be committed to it anyway.

Street thinks the realist is barred from giving this kind of response because realists are committed to the evaluative facts being independent of "all our evaluative attitudes" - including the unreflective, affective responses involved in pleasures and pains. But on this point Street is arguing against a straw man: I will offer textual evidence to show that realists such as Nagel and Parfit do not take realist evaluative facts to be independent of the unreflective, affective responses necessary for sensations to be pleasant or painful. A more useful definition of "realism," I suggest, is that the evaluative facts are independent of our beliefs or judgments.

\section{The challenge}

This section presents the core argument in Sharon Street's "A Darwinian Dilemma for Realist Theories of Value" (2006, henceforth Dilemma).

The argument relies on the empirical premise that evolutionary pressures have had a strong influence on the content of the evaluative judgments we find ourselves making. The claim is not that making specific evaluative judgments are heritable traits which have been selected for; rather, it is that certain basic 
evaluative tendencies are heritable and were selected, and that, in turn, these tendencies have a very strong influence on which evaluative judgments we make. A basic evaluative tendency "may be understood very roughly as an unreflective, non-linguistic, motivational tendency to experience something as 'called for' or 'demanded' in itself, or to experience one thing as 'calling for' or 'counting in favor of something else" (Dilemma, p. 119). As an example, she mentions the tendency of chimps to "experience the fact that someone helped them as 'counting in favor of helping the other in return" (ibid).

For the moment, let's accept the empirical premise and move on to the dilemma Street thinks it generates for the realist. Simply put, the dilemma is a challenge for the realist to make one of two assertions:

FIRST HORN: There is a relation between evolutionary pressures and the evaluative facts.

SECOND HORN: There is no such relation.

Since the dilemma-horns are a proposition and its negation, it does indeed look reasonable to demand of realists that they assert one or the other.

If realists opt for the SECOND HORN, Street argues that they are ultimately forced to an unacceptably sceptical position:

The key point to see about this option is that if one takes it, then the forces of natural selection must be viewed as a purely distorting influence on our evaluative judgements, having pushed us in evaluative directions that have nothing whatsoever to do with the evaluative truth. On this view, allowing our evaluative judgements to be shaped by evolutionary influences is analogous to setting out for Bermuda and letting the course of your boat be determined by the wind and tides: just as the push of the wind and tides on your boat has nothing to do with where you want to go, so the historical push of natural selection 
on the content of our evaluative judgements has nothing to do with evaluative truth. [...] Of course it's possible that as a matter of sheer chance, some large portion of our evaluative judgments ended up true, due to a happy coincidence [...] but this would require a fluke of luck that's not only extremely unlikely, in view of the huge universe of logically possible evaluative judgments and truths, but also astoundingly convenient to the realist. Barring such a coincidence, the only conclusion remaining is that many or most of our evaluative judgments are off track. This is the far-fetched skeptical result that awaits any realist who takes the route of claiming that there is no relation between evolutionary influences on our evaluative judgments and independent evaluative truths. (Dilemma, pp. 121-122)

If realists opt instead for the FIRST HORN, Street reasonably demands that they must give an account of this relation they posit between evolutionary pressures and evaluative facts. She then gives a two-step argument to show that realists cannot give any such account that is empirically acceptable.

The first step of this argument is, in my view, probably sound. Street proposes, on behalf of the realist, a possible account of the relationship between evolutionary pressures and evaluative truth, and then rejects this account. This is the "tracking account" mentioned in the introduction. The tracking account says that the ability to grasp evaluative truths is a reproductively beneficial, and therefore selected, ability in humans. To this, Street reasonably responds that it offers no reproductive benefit to grasp evaluative truths, as realists conceive of them. For instance, while it does carry a reproductive advantage to be disposed to believe that one has a duty to care for one's children, having this belief only if and because it is true (in the realist sense) adds no reproductive benefit.

The second step is (as we shall see) more problematic. After having disposed of the tracking account, Street claims that it was the only possible account realists could give: 
insofar as realism asserts any relation between selective pressures on our evaluative judgements and evaluative truths, the position is forced to give a tracking account of this relation. The reason for this stems from the very nature of realism itself. The essence of the realist position is its claim that there are evaluative truths that hold independently of all our evaluative attitudes. But because it views these evaluative truths as ultimately independent of our evaluative attitudes, the only way for realism both to accept that those attitudes have been deeply influenced by evolutionary causes and to avoid seeing these causes as distorting is for it to claim that these causes actually in some way tracked the alleged independent truths. There is no other way to go. (Dilemma, pp. 135-136)

\section{The plan}

This section explains the form my argument will take.

As mentioned, since the two horns of the Darwinian dilemma are a proposition and its negation, it does indeed look plausible to demand of realists that they assert one or the other. My plan, however, is to remain uncommitted. Instead, I will make two assertions, conditional upon the status of a substantive, evaluative claim, namely:

$P$ : Pleasure is usually good and pain is usually bad.

Two clarifications: first, $P$ should be understood as saying that pleasure is usually good for the person who enjoys it and pain usually bad for the person who suffers it. In the language of reasons: the fact that some event would give $x$ pleasure is a reason for $x$ to bring the event about, and the fact that some event would cause $x$ pain is a reason for $x$ to prevent the event from occurring. These claims contrast with the absolute or "agent-neutral" claims that pain is bad without implicit reference to anyone it is bad for ("bad full stop") and similarly for pleasure ("good full stop"). In reasons-lingo: the fact that some event would cause $x$ pain/pleasure is a rea- 
son for everyone to try to prevent it/bring it about, if they can. These absolute or agent-neutral claims will come up later on, but they are distinct from $P$.

Second, the "usually" makes $P$ a bit vague, but the following will hopefully suffice to clarify. The claim should be read as saying that the vast majority of cases of pleasure are good and of pain bad - but that there may be exceptional cases in which they are not. What precisely these exceptional cases would be does not matter to the argument, but it does matter that they be relatively rare. Of course, if pleasure is always good and pain always bad, $P$ also counts as true.

The two assertions I want to make are, first, that if pleasure is usually good and pain usually bad, then there is a relation between evolutionary pressures and the evaluative facts. And, second, that if it is not the case that pleasure is usually good and pain usually bad, then there is no such relation. In other words, I am asserting:

$$
\begin{aligned}
& P \rightarrow \text { FIRST HORN } \\
& n o t-P \rightarrow \text { SECOND HORN }
\end{aligned}
$$

Street's contention is that, if realists assert FIRST HORN, they cannot give any good account of this relation they posit between evolutionary pressures and evaluative truth. On the other hand, if they assert SECOND HORN, they are left with the "far fetched" result that "many or most" of our evaluative beliefs are probably false. Against this I want to argue, first, that realists can give an account of how, if pleasure is usually good and pain usually bad, there is a relation between Darwinian forces and the evaluative facts. Second, I want to argue that it is not far-fetched to think that, if pleasure is not usually good or pain not usually 
bad, then many or most of our evaluative beliefs are false. In other words:

$P \rightarrow$ the FIRST HORN is tenable.

not $-P \rightarrow$ the SECOND HORN is tenable

I'll argue these in turn in the next two sections. In section 4.5, I defend my account against an objection made by Street.

\section{A pre-established harmony account}

In this section, I argue from $P$ to the conclusion that evolutionary pressures have probably not introduced massive error in our evaluative belief system. I will give two nested arguments; first a simple core argument, and then a surrounding argument intended to show that the core argument is sufficiently powerful. The first argument shows that, if pleasure is usually good and pain usually bad, there does indeed exist a relation between evolutionary pressures and the evaluative facts, a relation which is truth-conducive in the sense that it would tend to bias our evaluative beliefs toward the truth. The second argument then attempts to show that this relation and this truth-conducive effect are sufficiently strong to allow realists to avoid the radically sceptical conclusion Street has in store for them.

Let me stress that that's all I will argue; I will not try to give a comprehensive mapping of evolution's impact on our evaluative beliefs, and I do not mean to imply that I think pleasures and pains are the only things that are good or bad. Nor is anything in this section intended to do the job of a general, realist moral epistemology.

The empirical premise of the Darwinian dilemma, recall, is that evolution- 
ary pressures have had a strong influence on our evaluative beliefs. But how has this influence exerted itself? An important part of the answer, I think, is this: evolution has caused us to value reproductively beneficial things by making us such that we take pleasure in these things, and caused us to disvalue reproductively harmful things by making us such that these things cause us pain.

These are empirical claims which you might want to check with your local biologist. But it is fairly easy to see the selective mechanism which would make them true. For brevity, I will only spell it out for pleasure, but parallel remarks regarding pain could be added in obvious ways.

It's a plain psychological fact about humans that we are motivated by pleasure, in the sense that we tend to be motivated to pursue activities and states of affairs that give us pleasure, because they give us pleasure. Presumably, our general capacity to feel and be motivated by pleasure is a product of evolution. One can speculate about why evolution has endowed us with this machinery, as opposed to, say, relying only on a tendency to be directly motivated by the belief that some action would promote survival and reproduction. The answer presumably involves the fact that our inherited traits are outgrowths of traits that have worked well further down in the phylogenetic tree, and that pleasure-taking dispositions have proved an efficient way to store information about the fitness of various activities and states in the genetic code. But since I take it to be uncontroversial that this general trait is the result of our evolutionary past, I'll put such questions aside.

Once we have the general capacity to feel and be motivated by pleasure on 
the table, it's easy to see how the rest of the story goes. Individuals that took pleasure in reproductively beneficial activities and states would tend to pursue those activities and states with greater vigour than individuals that did not. Therefore, the former individuals would tend to leave more offspring, with the result that their pleasure-taking dispositions over time would spread in the population (at least for those dispositions that were heritable). For instance, individuals that took pleasure in nutrient foods, sex, the welfare of their children, social status within their group, and so on, would tend to pursue these things with greater vigour than individuals that did not. Hence, given that pursuing these things with greater vigour increases the probability of getting them, and getting them tends to be reproductively beneficial, and given that these pleasure-taking dispositions are heritable, they would spread in the population.

So far, we have a mechanism that explains why we should be disposed to take pleasure in and be motivated to pursue reproductively beneficial activities and states of affairs. Our tendency to value, to judge good, in line with the first two dispositions is a third, further fact. But, like Street, I think it is evident that our "full-fledged" beliefs about evaluative matters are in fact heavily influenced by such more primitive attitudes (c.f. Dilemma, pp. 118-121). Given this, we have a mechanism through which evolution has caused us to be disposed - all the way up to full-fledged beliefs - in favour of reproductively beneficial activities and states of affairs.

But now if, as $P$ claims, pleasure is usually good (for the subject), then to the extent that evolution has influenced our evaluative beliefs through the mechanism just described, that influence has been truth-conducive. For if pleasure is usually good, then the 
activities and states of affairs evolution has caused us to value through this mechanism tend to be good - because they are pleasurable. Hence, if $P$ is true, there is a relation between reproductive enhancement and goodness after all.

Is this a version of the tracking account Street dismisses? In the most relevant sense of "tracking", it is not, because the account does not say that evolution has caused us to appreciate a set of pre-existing evaluative truths. Rather, the account says that evolution has created value and the corresponding attitudes, simultaneously. Hence, I think it is better to refer, as I will, to the account just given as a "pre-established harmony account"; if pleasure is (usually) good, then it was ordained ahead of time, as it were, that (almost) whatever evolution should happen to make us value through this mechanism, it would thereby also imbue with value. ${ }^{1}$

To be clear: the sense in which evolution has "created" value or "imbued" states of affairs with value is not that it has made their pleasurableness good. That (we are assuming in this section) is an independent evaluative fact. The role evolution has played is simply making these states of affairs pleasurable. But once evolution has done that, the independent evaluative fact "kicks in", as it were, the end result being that these states of affairs are good.

Street's argument that the first horn of the Darwinian dilemma is untenable for realists was that the only account realists can give of a relation between evolutionary pressures and the evaluative facts is the empirically implausible tracking

\footnotetext{
${ }^{1}$ I owe the use of the phrase "pre-established harmony" in this context to David Enoch (2009). Enoch offers a similar response to the Darwinian dilemma, but his argument is based on the assumption that survival is good, and he does not employ the separation-of-cases strategy that is central to my argument.
} 
account. The above argument shows in the most straightforward way, by actually giving a different account, that this claim is mistaken. But one may worry that the pre-established harmony account, even if it is correct as far as it goes, will nevertheless land realists over in the second horn of the Darwinian dilemma, because it only shows that one mechanism through which evolution has shaped our evaluative beliefs is truth-conducive (if $P$ is true). And it seems plausible that there are other such mechanisms, which the account does not cover, and which the realist must still consider "distorting influences". One may worry that, overall, enough evolutionary influence upon our evaluative beliefs remains unaccounted for, so that realists are still pushed to the unacceptably sceptical conclusion that, probably, many or most of our evaluative beliefs are false.

I believe the pre-established harmony account is in fact enough for the realist to avoid this conclusion, for two reasons (these comprise the "surrounding argument" advertised above). First, I simply want to voice scepticism about the strength of Darwinian influences, beyond the mechanism involving pleasures and pains, upon our evaluative beliefs. While we can't help but think that it is bad to starve, to have our arms and legs broken, or to be shunned by everyone we know, it seems we can help but embrace the beliefs corresponding to other kinds of innate evaluative tendencies.

In Street's article, we find three examples of innate basic evaluative tendencies that seem unrelated to pleasures and pains: first, a disposition towards reciprocity; toward taking the fact that someone has treated us well to count in favour of treating the other well in return, and similarly for answering ill with ill. Second, a disposition to appreciate altruism, i.e. taking the fact that someone has acted 
altruistically to be a reason for a positive assessment of that person. Third, a disposition to accord moral status according to social status, i.e. to accord lesser treatment to members of "out-groups" than to members of the "in-group" (Dilemma, pp. $113,115-116)$.

But basic evaluative tendencies such as these clearly have a weaker impact upon our evaluative beliefs than pleasures and pains. For instance, of the three evaluative tendencies above, Christian ethics rejects the first (c.f. e.g. Luke 6: 27-35), Nietzsche and some of his followers reject the second, and most people I know reject the third. ${ }^{2}$ Thus, if these kinds of evolutionary influence are all the would-be anti-realist debunker can point to besides the pleasure-pain mechanism, I can see no reason why the realist should be forced to the sceptical conclusion that evolutionary pressures probably have left us hopelessly off track in our evaluative beliefs.

I don't expect these quick remarks to settle the issue; clearly there is room for further argument. But I think the above argument shows that the anti-realist debunker must move beyond the general claim that evolution has had a profound impact upon our evaluative beliefs. For the pleasure-pain mechanism may well be the main thing that makes this general claim true, and as I have argued, if we assume the truth of $P$, then that mechanism is truth-conducive.

\footnotetext{
${ }^{2}$ One might think that, similarly, there are relatively common moral views which reject the goodness of pleasure and the badness of pain. But I do not think that these views really fail to judge pain intrinsically bad and pleasure intrinsically good. For instance, if I understand Buddhist doctrine correctly, pleasure is taken to be bad because it helps bind us to a mode of existence that prevents the cessation of pain. In certain ascetic versions of Christianity, pain is taken to have a good and pleasure a bad effect upon the soul.
} 
The second reason why I believe the pre-established harmony account is enough to counter Street's argument is that realists are likely to have a different view than Street about how far in the direction of scepticism we can allow our moral epistemology to go before it becomes "far-fetched". Compared to standard forms of anti-realism, realism with respect to any domain will predict a greater risk of doxastic error in that domain. That is part of the package: indeed, one possible motivation for being a realist is that one thinks anti-realism predicts too little risk of error.

The overall picture that emerges for the realist from the above discussion is that, given $P$, evolutionary forces have been truth-conducive in the core area of our evaluative thinking concerning nourishment and health, happiness, social standing, sex, etc., where they have also been strongest. In other more peripheral areas, Darwinian forces may well have been truth-adverse, but in these cases the Darwinian forces also seem weaker.

I submit that a realist with healthy epistemic nerves can live well with this picture. The conclusion of the $P$ branch of my argument, then, is that conditional upon the assumption that $P$ is true, realists can give an empirically plausible account of a relation between evolutionary pressures and the evaluative facts, and are thus not forced to any dramatical sceptical conclusion.

\section{If we are wrong, then we are wrong}

In this section, I argue from not- $P$ to the conclusion that many or most of our evaluative beliefs are false. The conclusion of the argument, then, is the conditional: if not- $P$, then many or most of our evaluative beliefs are false. Since this 
conditional is true, I then claim, it is not a problem for moral realists to be committed to it.

Assume for the sake of argument that $P$ is false; that it is not the case that pleasure is usually good and pain usually bad. Then either pleasure is not usually good, or pain is not usually bad, or both. Suppose, first, that pleasure is not usually good. As discussed in Sect. 2, this is to be understood in the agentrelative sense, as the claim that pleasure is not usually good for the person who enjoys it. Now consider the great number of our beliefs that must be false if this is false. For instance, we think (other things equal) that we have more reason to eat food we like than food we dislike; that people who enjoy opera music have more reason to go to the opera than people who don't; that a happy day at the beach is preferable to a boring day at the office; that riding business class is preferable to riding in economy. If pleasure is in fact not usually agent-relatively good, then most of our beliefs along these lines are false.

Further, if a given case of pleasure is not good for the person who enjoys it, then it is hard to see how it could be good in the absolute sense ("good full stop"). In reasons-lingo, if the fact that some event would bring $x$ pleasure is not a reason for $x$ to bring it about, then it is hard to see how this fact could be a reason for other people to bring the event about. Thus, I take it, if pleasure is not usually good in the agent-relative sense, then neither is it usually good in the agentneutral sense. Now consider the belief that, other things equal, lifting other people's spirits is better than making them depressed; that a rich person has more reason to use her fortune to build a beautiful public park than to throw the money in the sea; that army cooks have reason to try to make the chow tasty. If 
pleasure is in fact not usually agent-neutrally good, then these and similar beliefs tend to be false.

Suppose next that pain is not usually bad. As before, this is to be understood in the agent-relative sense. Now consider the following beliefs: that the fact that it would hurt is a reason not to hit ourselves with a hammer; that the fact that it would stop our headache is a reason to take an Aspirin; that it is better to have root-canal surgery with anaesthesia than without it. If pain isn't usually agentrelatively bad, then most of our beliefs along these lines are false.

By a similar reasoning as above, I take it that, if pain isn't usually bad in the agent-relative sense, then neither is it usually bad in the agent-neutral sense. Thus most of our beliefs of the following kind will be false as well: that we have a reason not to torture people, that we have reason to give aspirin to people with headaches, etc.

Beliefs of these kinds make up large sections of our total body of evaluative beliefs. If pleasure isn't usually good, then, or pain isn't usually bad, large portions of our body of evaluative beliefs contain many falsehoods. But then many of our evaluative beliefs are false. Depending upon just how large a fraction of our evaluative beliefs are tied up with pleasure and pain, and upon how seldom pleasure and pain in fact are good/bad, the upshot could even be that most of our evaluative beliefs are false.

If $P$ is false, then, many or most of our evaluative beliefs are false. But then it is not a problem for a metaethical theory that it has the consequence that if $P$ is false, many or most of our evaluative beliefs are probably false. That is exactly as 
it should be. If it is not the case that pleasure is usually good and pain usually bad, then on my view there is no relation between evolutionary pressures and the evaluative facts. As Street argues, if there is no such relation, then it follows that many or most of our evaluative beliefs are probably false. But again, if $P$ is false, then many or most of our evaluative beliefs are false. It is not an objection to a map that it fits the terrain.

The conclusion of the not- $P$ branch of my argument, then, is that conditional upon the assumption that $P$ is false, moral realists can happily embrace the FIRST HORN of the Darwinian dilemma.

\section{$5 \quad$ "Realism" and pain}

Street anticipates a realist response similar to the pre-established harmony account, but argues that it is illegitimate for realists to appeal to pleasure and pain in the way that argument does. To see why, we must examine in some detail her definition of "realism" together with her account of pain.

First, realism. "The defining claim of realism about value, as I will be understanding it," Street says, "is that there are at least some evaluative facts or truths that hold independently of all our evaluative attitudes." By "evaluative attitudes" she means "states such as desires, attitudes of approval and disapproval, unreflective evaluative tendencies such as the tendency to experience $\mathrm{X}$ as counting in favor of or demanding Y, and consciously or unconsciously held evaluative judgments" (Dilemma, p. 110). She adds, in an endnote, "More broadly, realism about value may be understood as the view that there are mind-independent evaluative facts or truths. I focus on independence from our evaluative attitudes because 
it is independence from this type of mental state that is the main point of contention between realists and antirealists about value" (ibid, nl, p. 156).

I will dispute this definition of "realism" in a moment, but first it will be helpful to get on the table what is at stake. Street considers the following realist response to the Darwinian dilemma:

There are obvious evolutionary explanations of why we tend to feel physical pain when we do: roughly, we tend to feel it in conjunction with bodily conditions or events that diminish reproductive success [...] Pain itself, moreover, due to its very nature, is bad independently of whatever evaluative attitudes we might hold. Together these points provide at least a rough answer to the question of what the relation is between evolutionary pressures and independent evaluative truths: in short, evolutionary pressures led us to feel pain under suchand-such kinds of circumstances, and that experience is, of its very nature, bad independently of all our evaluative attitudes, its badness therefore demanding a realist construal. (Dilemma, pp. 144-145)

As we see, this is roughly the pre-established harmony account. But Street thinks realists can't point to pain as a case of attitude-independent badness, simply because the existence of pain isn't attitude-independent. To show this, she uses another dilemma argument, which she calls the Pain Dilemma. She challenges the realist to either accept or deny the following statement (Dilemma, pp. 37, 39-40):

$\mathcal{N}:$ It is a necessary condition for a sensation's being a pain that the creature having it unreflectively takes it to count in favor of doing whatever would avoid, lessen, or stop it 
Street further explains $\mathcal{N}$ thus:

according to $[\mathcal{N}]$, if a creature does not at an unreflective level take a given sensation to "count in favor of" doing what would alleviate it - in other words, if a creature has a sensation that it in no way feels motivationally "pushed" or "pulled" to avoid, lessen, or stop - or if, more complexly, the creature feels no distress at the sensation's presence, no relief when it subsides, and so on - then the sensation in question does not count as a pain. (Dilemma, p. 146)

The first dilemma-horn Street considers on behalf of the realist is denying $\mathcal{N}$. Then, she argues, the realist would commit herself to the conceptual possibility that "instead of disliking pain the way we all happen to do, we could naturally enjoy it and be inclined to seek it out, unreflectively experiencing it as counting in favor of what would cause it" (ibid, p. 148). This horn of the dilemma, then, is highly implausible.

With regards to the other option, accepting $\mathcal{N}$, Street writes:

[this] is just to admit that the badness of pain depends in an important sense on our evaluative attitudes - in particular on our being unreflectively inclined to take it to be bad. Pain may well be bad, in other words, but if it is so, its badness hinges crucially on our unreflective evaluative attitudes toward the sensation which pain is. The realist is thus forced to recognize the role of our evaluative attitudes in determining the disvalue of pain. ( $D i^{-}$ lemma, p. 151)

Accepting $\mathcal{N}$, then, is the same as admitting that the badness of pain isn't independent of all our evaluative attitudes, which, recall, was Street's criterion for realist evaluative facts. If the Pain Dilemma succeeds, then, the pre-established harmony account fails to establish a relation between selective pressures and evaluative facts realistically construed.

However, the apparent force of the Pain Dilemma depends entirely upon its slippery terminology. It takes no less than four different kinds of mental state, and 
treats them as if they were all the same. They are (c.f. various quotes above):

1. Negative phenomenology. (Dislike. Feel distress at presence of.)

2. Motivational states. (Unreflectively take to "count in favor of" doing what would alleviate... in other words, feel motivationally "pushed" or "pulled" to avoid, lessen, or stop.)

3. Beliefs or quasi-beliefs about reasons. (Unreflectively take to count in favor of doing whatever would avoid, lessen, or stop.)

4. Beliefs or quasi-beliefs about value. (Unreflectively take to be bad.)

I have ranked these from the most primitive to the most conceptual (though it is debatable whether levels 3 and 4 are interestingly different in this respect). Street's official formulation is on level 3: this is the state which according to $\mathcal{N}$ is necessary for a sensation to be a pain. When explaining $\mathcal{N}$, however, she goes one level down, to level 2, where (take to) "count in favour of" is in scare-quotes, and really means "feel motivationally 'pushed' or 'pulled". Then, when she discusses what the realist commits herself to in denying $\mathcal{N}$, we go all the way down to level 1: now the realist has apparently denied that it is necessary that we dislike a sensation for it to be a pain.

On the other hand, when discussing what the realist commits herself to in $a c^{-}$ cepting $\mathcal{N}$, we take a step up, to level 4 : we now have that $\mathcal{N}$ involves unreflectively taking to be bad.

It is an interesting question exactly what the affective (let this be a neutral term) response involved in pains is (whether we say that the affect is necessary for a sensation to count as a pain, or whether we say that the sensation plus the 
affect together constitute the pain). But there is no need to decide that question here. Instead, I will argue the following: responses on levels 3 or 4 are not necessary for painfulness; and realists do not claim that the evaluative facts are independent of responses on levels 1 or 2.

If we read $\mathcal{N}$ on levels 3 or 4 , as it were, i.e. read "take to be bad" and "take to count in favor of" literally, as describing beliefs or quasi-beliefs, then it is hopeless to argue that these states are necessarily involved in pains. That would for instance make it impossible for animals that lack conceptual thought to feel pain.

If we consider the states on level 1, disliking and feeling distress, then we do indeed have plausible candidates for states which are necessary for sensations to count as pains. But then, realists do not claim that the evaluative facts are independent of our likes and dislikes; for instance, Parfit's account of pain explicitly invokes level 1 states:

Another important set of mental states, though they are often assumed to be desires, are better regarded as being in a different category. These are the hedonic likings or dislikings of certain actual present sensations that make our having these sensations pleasant, painful, or in other ways unpleasant, or in which their pleasantness or unpleasantness partly consists. (D. Parfit, unpublished manuscript, §6)

But, of course, if Parfit isn't a realist about the badness of pain, no one is. (I will discuss what I think such realism involves below.) It should be mentioned that this part of Parfit's manuscript was written after the publication of Dilemma 
(Street, pc).

It isn't obvious whether states on level 2, i.e. motivational states, are really necessary for sensations to be painful. But Thomas Nagel apparently thinks they are: "Physical pleasure and pain $[\ldots]$ are just sensory experiences in relation to which we are fairly passive, but toward which we feel involuntary desire or aversion" and again "the sufferer's reaction is very clear. Of course he wants to be rid of this pain unreflectively..." (1986, pp. 156, 161). Nagel, then, seems to accept $\mathcal{N}$ on its level 2 interpretation. But he also takes the badness of particular pains to be paradigmatic examples of realist (his term is "objective") evaluative facts (ibid, p. 156). So Nagel must either be completely confused, or he and Street must mean different things by "objective" and "realist", respectively.

This brings us back to Street's definition of realism in terms of independence from "all evaluative attitudes". We now see what is at stake in defining "realism" in this way. Thirty-five pages after the definition is offered, we learn that Street will include also the unreflective, affective responses involved in pleasures and pains in the class of evaluative attitudes. Together, this explicit definition of "realism" and implicit definition of "evaluative attitudes" allows Street to impute to realists the bizarre commitment that, in effect, the evaluative facts are independent of our pleasures and pains!

The exact nature of the affective response involved in pain is really beside the point here, the point is that, if we make it clear that our definition will require realist evaluative facts to be independent of all our evaluative attitudes including the unreflective attitudes (whatever exactly they be) necessary for sensations to be pleas- 
ant or painful, then realists would have no reason to accept the definition. They never meant to claim that realist evaluative facts are mind-independent in that sense.

Of course, I cannot show that this interpretive claim holds for every realist; a few representatives will have to do. We have already seen that it would be hopeless to understand Nagel or Parfit's views as requiring evaluative facts to be independent of all evaluative attitudes, in Street's sense. In addition, we can consider Shafer-Landau, to whom Street refers in the section where she introduces her preferred definition. If we follow the reference, we find that SchaferLandau's official definition is this: "Realists believe that there are moral truths that obtain independently of any preferred perspective, in the sense that the moral standards that fix the moral facts are not made true by virtue of their ratification from within any given actual or hypothetical perspective. That a person takes a particular attitude toward a putative moral standard is not what makes that standard correct" (2003, p. 15, original italics).

The notion of "ratification" from within a "perspective" is open to interpretation, but the surrounding discussion indicates that it is independence from $b e^{-}$ liefs Schafer-Landau has in mind: "Realism is sometimes described as the view that moral truths are evidence-transcendent. [...] If evidence is restricted to beliefs, then this tallies with my conception" (ibid, p. 16, my italics). Again: "realism $[\ldots]$ insists that the truth of any first-order normative standard is not a function of what anyone happens to think of it," and: "realists are committed to the idea that a moral standard might be correct even if no actual person believed it to be; indeed even if everyone renounced it" (ibid, pp. 15, 17). 
To be clear, Street never claims to be giving a definition of "realism" as it is used by others; as I quoted above, she only characterizes realism "as I [Street] will be understanding it" (Dilemma, p. 110). So my objection here is not technically that the definition is wrong; I do however hope to have shown that, if the definition is to do the work needed to support the Pain dilemma, it does so at the cost of leaving Street without Parfit, Nagel, and probably Shafer-Landau as actual opponents. In fact, I am not aware of any realist theories that would be affected by the argument.

Let me in closing try to put these points about what realism (about value in general and about the badness of pain in particular) isn't in context by spelling out what I think it is. As also suggested in the quotes from Schafer-Landau, I think realism about value is best understood as the view that the evaluative facts are independent of our beliefs or judgments. Realism about the badness of pain, then, is the view that anyone who makes the judgment "this pain isn't bad," whilst actually being in pain, is in error. (Though, again, I think there may be exceptional cases in which pain isn't bad. In such cases, if there are any, anyone who makes the judgment "this pain is bad" is in error). It should be clear that the pain dilemma does nothing to threaten this view.

\subsection{Conclusion}

I have argued that combining moral realism with Darwinism does not lead to unacceptable results in moral epistemology if we assume that $P$ is true, nor if we assume that $P$ is false. I believe these conditional, or "iffy", claims - as opposed to categorical claims about how much moral knowledge we do or do not have 
offer realists our strongest line of defence against Street's challenge. ${ }^{3}$ Hence the essay's title.

In addition to this argumentative strategy, the "pre-established harmony account" given in section 4.3 is the main positive contribution of this paper. This account showed that, if we assume $P$, it follows that there exists a truthconducive relation between Darwinian forces and the evaluative facts. A surrounding argument was then given to show that this relation and this truthconducive effect are sufficiently strong to land the moral realist in an epistemological scenario which is not unacceptably sceptical. The main points were that the Darwinian forces seem strongest precisely where they are also truthconducive, and that we can live with the realization that they may have been truth-adverse in other areas where they have been less strong.

While the pre-established harmony account seems incontrovertible, the surrounding argument is admittedly less conclusive. It seems to me that the final verdict depends, in part, upon empirical questions of how strong and wideranging the evolutionary influence has been, but also upon the philosophical question of how far in the direction of scepticism the realist can allow herself to go before she should turn back and go down the anti-realist path instead. A third kind of question that I have not discussed is the role of other non-epistemic influences, such as political and economic pressures, upon our evaluative beliefs. Clearly, there is much room for further argument.

However, the ambition of this paper is not to get the final word on this mat-

\footnotetext{
${ }^{3}$ In fact I believe defending conditional claims of this kind is the best way to answer scepticism generally, but that's a topic for another day.
} 
ter, but to deny it to Street — or at least to Street (2006). The Darwinian dilemma does not, I have argued, succeed in closing the door on realist moral epistemology. If we are right about pleasure and pain, then we can reasonably believe that evolutionary forces have not driven us too far astray; and if we are wrong about pleasure and pain, we can be sure that they have, but then we would be lost anyway. 


\section{References:}

Bergström, Lars (1990); Grundbok i värdeteori. Stockholm: Thales

Blackburn, Simon (1971); "Moral Realism" in Morality and Moral Reasoning, ed. John Casey, London: Methuen.

Blackburn, Simon (1985); "Supervenience Revisited" in Exercises in Analysis: Essays by Students of Casimir Lewy, ed. Ian Hacking, Cambridge, Cambridge University Press

Blackburn, Simon (1993); Essays in Quasi-Realism, OUP

Blackburn, Simon (2009); "Truth and A Priori Possibility: Egan's Charge Against Quasi-Realism" in Australasian Fournal of Philosophy

Boyd, Richard N (1988). "How to be a moral realist." in Essays on Moral Realism, Geoffrey Sayre-McCord (ed.), Ithaca, Cornell University Press

Bratman, Michael (2006); "Thinking How to Live and the Restriction Problem" in Philosophy and Phenomenological Research

Bratman, Michael (2008); "Normative Thinking and Planning, Individual and Shared: Reflections on Allan Gibbard's Tanner Lectures" in Gibbard (2008)

Brink, David (1989); Moral Realism and the Foundations of Ethics, Cambridge University Press

Burgess, John P. (2007); “Against Ethics” in Ethical Theory and Moral Practice

Bykvist, Krister and Olson, Jonas (2009); "Expressivism and Moral Certitude" in The Philosophical Quarterly Vol. 59, No. 235

Carlson, Gregory N (1977); Reference to Kinds in English, PHD Dissertation, University of Massachusetts, Amherst

Cuneo, Terrence (2006); "Saying What We Mean: an Argument Against Ex- 
pressivism" in Oxford Studies in Metaethics, vol 1.

Darwall, Stephen; Gibbard, Allan; Railton, Peter (1992); “Toward fin de siecle ethics: some trends" in The Philosophical Review

Davidson, Donald (1980); Essays on Actions and Events, OUP

Drai, Dalia (2000); "Moral Supervenience and Moral Thinking" in Disputatio, vol. 8

Dreier, James (1992); "The supervenience argument against moral realism" in The Southern Fournal of Philosophy, Vol. XXX, No. 3

Dreier, James (2006); "Negation for expressivists: a collection of problems with a suggestion for their solution" in Oxford Studies in Metaethics, vol. 1, Russ ShaferLandau (ed.), OUP

Egan, Andy (2007); "Quasi-realism and fundamental moral error” in Australasian Journal of Philosophy

Enoch, David (2005); "Why Idealize?”, in Ethics

Enoch, D. (2009). "The epistemic challenge to metanormative realism: How best to understand it, and how to cope with It." in Philosophical Studies

Enoch, David (2011); Taking Morality Seriously, OUP

Faraci, David (2012); How to Be (and How Not to Be) a Normative Realist, PHD dissertation, Bowling Green State University

Fine, Kit (2005); Modality and Tense, OUP

Gibbard, Allan (1990); Wise Choices, Apt Feelings, Harvard University press

Gibbard, Allan (2003); Thinking How to Live, Harvard University Press

Gibbard, Allan (2006); "Reply to Critics" in Philosophy and Phenomenological Research 
Gibbard, Allan (2008); Reconciling our Aims. In search of Bases for Ethics. OUP

Gibbard, Allan (201 1); "How Much Realism?" in Oxford Studies in Metaethics, vol. 6

Gibbard, Allan (2012); Meaning and Normativity, OUP

Gill, Michael (2009); "Indeterminacy and variability in metaethics" in Philosophical Studies

Hare, R. M. (1952); The Language of Morals, OUP

Hawthorne, John (2002); "Practical Realism?" in Philosophy and Phenomenological Research

Husi, Stan (2011); "Why Reasons Skepticism is Not Self-Defeating" In European Journal of Philosophy

Hussain, Nadeem and Shah, Nishi (2006); "Misunderstanding Metaethics: Korsgaard's Rejection of Realism" in Oxford Studies in Metaethics, vol 1

Jackson, Frank (1998): From Metaphysics to Ethics, OUP

Joyce, Richard (2001); The Myth of Morality, Cambridge University Press

Kahane, Guy (2012); "Must Metaethical Realism Make a Semantic Claim?" in Journal of Moral Philosophy

Korsgaard, Christine (1996): The Sources of Normativity, Cambridge University Press

Koslicki, Kathrin (1999); "Genericity and Logical Form" in Mind and Language, Vol.14, No.4

Kramer, Matthew (2009); Moral Realism as a Moral Doctrine, Wiley-Blackwell

Leslie, Sarah-Jane (2008); "Generics: Cognition and Acquisition" in The Philosophical Review 
Lewis, David (1974); "Radical interpretation" in Synthese

Lewis, David (1983); "New Work for a Theory of Universals" in Australasian Foumal of Philosophy, vol. 61, 4

Lewis, David (1989); "Dispositional Theories of Value" in Proceedings of the Aristotelian Society

Liebesman, David (2011); "Simple Generics" in Nous, vol. 45:3

Miller, Alexander (2003); An Introduction to Contemporary Metaethics, Cambridge, Polity Press

Moore, G. E. (1903); Principia Ethica, Cambridge University Press

Moore, G. E. (1922); "The Conception of Intrinsic Value" in International Library of Philosophy: Philosophical Studies, Routledge and Kegan Paul

Murphy, Liam (2008); "Better to See Law This Way" in NYU Law Review

Nagel, Thomas (1986): The View from Nowhere, OUP

Nagel, Thomas (1996): "Universality and the reflective self" in Korsgaard, Christine: The Sources of Normativity, Cambridge University Press

Nagel, Thomas (1997); The Last Word, OUP

Oddie, Graham (2005); Value, Reality, Desire, OUP

Parfit, Derek (2011); On What Matters, OUP

Scanlon, T. M. (2003); "Metaphysics and Morals" in Proceedings and Addresses of the American Philosophical Association

Scanlon, T. M. (2006); "Reasons and Decisions" in Philosophy and Phenomenological Research

Schroeder, Mark (2008); Being For: Evaluating the Semantic Program of Expressivism, 


\section{OUP}

Shafer-Landau, Russ (2003); Moral Realism - A Defence, OUP

Skarsaune, Knut Olav (2011); "Darwin and Moral Realism: Survival of the Iffiest" in Philosophical Studies

Smith, Michael (1994); The Moral Problem, OUP

Smith, Michael (2002); "Evaluation, Uncertainty and Motivation" in Ethical Theory and Moral Practice 5: 305-32

Street, Sharon (2006); "A Darwinian Dilemma for Realist Theories of Value" in Philosophical Studies

Street, Sharon (2008); "Constructivism about reasons" in Oxford Studies in Metaethics, vol. 3, Russ Shafer-Landau (ed.), OUP

Street, Sharon (2009); "In Defence of Future Tuesday Indifference" in Philosophical Issues

Street, Sharon (2011); "Mind-Independence without the Mystery; Why QuasiRealists Can't Have it Both Ways" in Oxford Studies in Metaethics, vol. 6, Russ Shafer-Landau (ed.), OUP

The Stanford Encyclopedia of Philosophy (2008); Moral Non-Naturalism. Available (as of January 10th 2012) at: http://plato.stanford.edu/entries/moralnon-naturalism/

Timmons, Mark (1999); Morality Without Foundations, OUP

Unwin, Nicholas (1999); “Quasi-Realism, Negation and the Frege-Geach Problem" in The Philosophical Quarterly

Wilson, Jessica (2010); "What is Hume's Dictum, and Why Believe It?" in Philosophy and Phenomenological Research, vol. 80, p. 595-637 